\title{
Early cardiac change after menopause-an open level comparative study
}

\begin{abstract}
Cardiovascular disease (CVD) is one of the leading causes of death worldwide which is more prevalent in women after menopause. Hormonal changes associated with menopause are accountable for dyslipidemia pattern that causes CVD and associated complications. Therefore, the present study was commenced to compare the lipid profile in pre- and postmenopausal women. A total of 100 samples were collected from women, 50 from premenopausal and 50 from postmenopausal women, and analyzed for Total Cholesterol (TC), Triglyceride (TG), High-Density Lipoprotein (HDL) and Low-Density Lipoprotein (LDL-). TC, TG, HDL, and LDL were highly significantly increased in postmenopausal women when compared to premenopausal women. DL/HDL ratio was significantly elevated in postmenopausal women than in premenopausal women. MI was significantly positively correlated with TC and TG in both pre- and postmenopausal population and it was positively correlated with HDL in the premenopausal population while negatively correlated in the postmenopausal population. Since more of the atherogenic lipid parameters are increased in postmenopausal women, they appear to be more prone to have CVD and associated complications in the near future. Hence, it is mandatory to monitor and manage dyslipidemia patterns in every woman experiencing menopause. To investigate whether menopause may induce left ventricular structural and functional adaptations in normotensive and hypertensive women, we compared in a case-control setting 50 untreated hypertensive premenopausal women with 50 postmenopausal women and 50 normotensive premenopausal women with 50 postmenopausal women. Subjects were individually physically examined \& matched by age $(38.2 \pm 5$.9years to $50 \pm 1.03$ years), clinic systolic blood pressure $(128.6 \pm 1.05 \mathrm{~mm} \mathrm{Hg} \& 134 \pm 1.2 \mathrm{~mm} \mathrm{Hg})$, clinic diastolic blood pressure $(74.6 \pm 1.3 \mathrm{~mm} \mathrm{Hg} \& 74.6 \pm 1.2 \mathrm{~mm} \mathrm{Hg})$, and body mass index $(55.3 \pm 8.8 \mathrm{~kg}$ to $55.6 \pm 5.9 \mathrm{~kg})$ respectively. We conclude that menopause is associated with blunted day-night blood pressure reduction, impaired left the ventricular systolic performance, and concentric left ventricular geometric pattern. These findings are independent of the presence or absence of high blood pressure.
\end{abstract}

Keywords: menopause, coronary heart disease
Volume 12 Issue 2 - 202I

\author{
TH Johra Moon Moon,' Masuma Amanullah, ${ }^{2}$ \\ Nasima Akhter, ${ }^{2}$ M Moniruzzaman, ${ }^{3}$ Md \\ Abdullah Hil Kafi Khan, ${ }^{4}$ Md Shariful Islam ${ }^{5}$ \\ 'MBBS, FCPS, MS (Obs \& Gynae), Infertility Specialist \& \\ Laparoscopic Surgeon, Assistant Professor (Obs \& Gynae \\ Department), Aalok Health Care \& Hospital Ltd, Bangladesh \\ 2Junior consultant (Obs \& Gynae Department), Aalok Health \\ Care \& Hospital Ltd, Bangladesh \\ ${ }^{3}$ Senior Pharmacist, Ahsania Mission Cancer and General \\ Hospital, Bangladesh \\ ${ }^{4}$ Department of Pharmacy, Primeasia University, Bangladesh \\ ${ }^{5}$ Senior Product Development, Liberty Business Associates, \\ Bangladesh
}

Correspondence: Md Shariful Islam, Senior Product Development, Liberty Business Associates. Uttara Model Town, Dhaka, 1230, Bangladesh, Email sharif.seu17@gmail.com

Received: April 05, 2021 | Published: April 26, 2021

\section{Introduction}

When a woman's menstrual cycle stops permanently, she reaches a stage in life called menopause. Because of these life changes, this section eliminates a woman's ability to conceive. Many health care providers use the term menstruation to determine when female hormone levels begin to change. Menopause ends when the menstrual cycle ends one year. ${ }^{1-12}$

Women with a premature menopause $(<40$ years) are at increased risk of developing CVD, either naturally or surgically. The relationship between late structure and coronary heart disease (CVD) is well established. Observational studies have shown an increased risk of heart disease, lower numbers in the aorta, and more severe atherosclerosis in postmenopausal women. Menopause has recently been included in Framingham's Risk Assessment Work to Measure the Risk of Heart Disease in Women. Besides, the risk of rupture decreases when menopause occurs later. In contrast, later menopause is associated with endometrial breast cancer and ovarian cancer, and hepatocellular cancer. However, the risk of open cancer appears to below. $^{13-16}$

There is evidence that women of any age with vasomotor symptoms have a higher risk of heart condition (CVD, CHD, or stroke) than women without vasomotor symptoms. Women with vasomotor symptoms have higher systolic and diastolic blood pressure, higher levels of circulating cholesterol, and a higher body index than their asymptomatic counterparts. The mechanisms of beneficial cardiovascular effects of estrogen are often and partially known. Estrogens positively affect lipid profiles and this component ranges from ' $25 \%$ to $50 \%$ of its beneficial effect on heart disease. Estrogens protect LDL from oxidation and increase cell resistance to the cytotoxic effects of oxidized LDL. ${ }^{10}$

Furthermore, there is a better improvement in cell regeneration in postmenopausal women. Recent descriptions of receptors activated by writing on cardiac myocytes and fibroblasts have increased the potential for the physiological effects of estrogen on myocardial cells. There is also evidence that significant sex-specific conditions and sex hormones with the heart have significant cardio regulatory effects. Disappointment. The effects of menopause on the structure and function of menopause in the left ventricle, as well as the role of menopause concerning heart and blood pressure, have not been fully investigated. ${ }^{17-22}$

The current study is designed to assess the formation and efficacy of premenopausal and postmenopausal hypertension (LV) in women with significant untreated, age-related hypertension, BP, and weight index. Physical condition-control design. Two groups of normal women were studied before and after menopause to assess the physiological changes caused by menopause in the general study. 
Structural changes are a good time to treat and deal with cardiovascular risks such as diabetes, high blood pressure, and hyperlipidemia. Proper treatment guidelines for these risks are provided by the American Heart Association. Women with 1 to 1.5 drinks a day increase their risk of toxins, breast cancer, and cirrhosis. Most doctors do not always recommend the use of alcohol for heart protection in their female patients. ${ }^{23}$

Women appear to be at greater risk for the negative effects of alcohol, and even moderate drinking can lead to poisoning, cirrhosis, and an increased risk of breast cancer. Regular physical activity, which includes a moderate 30-minute activity on most days of the week, is associated with a reduced risk of cardiovascular events. Currently, there is no role for hormone therapy in the avoidance of heart disease. Regular use of aspirin to prevent myocardial infarction in low-risk women under 65 years of age is not indicated. In the recent past, an article was published which shows the activities and effectiveness of raloxifene in case of various cardiovascular conditions \& breast cancer. $^{23}$

Cardiovascular disease is a very serious health problem found in all parts of the world including Bangladesh. In Bangladesh, women comprise more than $50 \%$ of the population among most people over the age of 40. In particular, this group of people lacked physical activity due to their retired health; also, the consumption of unhealthy foods makes them more prone to suffering from atherogenic effects. This is a menopause transition that suggests that many Bangladeshi women are at risk of developing heart-related complications, which is a concern.

\section{Objective}

The purpose of this study was to identify the risk of heart disease in women, which is very important for public health. Early heart changes are associated with an increase in heart disease in some populations, mainly white populations, but they are not constant. Our specific goal is to find out if a woman is at risk for coronary heart disease or stroke in the future.

\section{Materials and methods}

A very detailed study of women was conducted for 12 months (January 2017 to December 2017) in Mirpur, Kaka. There were female participants in the study population for the first hospital-based visit to Islamia Bank in Kaka, Mirpur. There were 100 women aged 38.2 and 5.9years and 1.03years aged 50years. Of these, 50 were postmenopausal women, 50 were menopausal, 50 were menopausal, 50 were menopausal, 50 were menopausal, and 50 were menopausal. Lipid profiles of 50 postmenopausal patients and 50 postmenopausal patients were also studied.

The current study is based on questions from baseline tests, questionnaires, anthropometric measurements, and blood draw calculations. All participants were given written permission and this method is accepted in the medical ethics of Bangladesh.

\section{Menopausal status assessment}

The number of participants was divided into different distinct groups which based on the menstrual cycle and it may be defined as premenopausal, menopausal disease, and menopausal mutations. The group allocation was based on the knowledge of the basic questions and followed by the sections of the Maternity Working Process. Women with a normal menstrual cycle are currently classified as premenopausal. Women with irregular menstrual cycles for months or years were considered perimenopausal. Women who answered that they were postmenopausal when asked about routine menstruation, and on the day of menopause more than one year before the visit, were considered postmenopausal.

\section{Cardiovascular risk factor assessment}

On the baseline examination, height and weight were measured by trained staff from which body mass index $\left(\mathrm{BMI} ; \mathrm{kg} / \mathrm{m}^{2}\right)$ was calculated. Systolic and diastolic blood pressure (SBP and DBP) were measured 10 times over the course of 10 minutes using the day map PRO (GE Healthcare, Freiburg, Germany) from where the mean values were used. ${ }^{24}$ Baseline examination included rapid venous blood clearance. After direct blood withdrawal, predetermined biomarkers in each fasting blood sample were routinely evaluated in the inhouse laboratory of Islamic Bank Hospital, Mirpur, Dhaka. Serum levels of total cholesterol (TC) and high-density lipoprotein (HDL) were assessed with an enzymatic colorimetric method, low-density lipoprotein (LDL) was assessed with a colorimetric method, and triglyceride (TG) levels were measured with a colorimetric ultraviolet method, with a Roche Modular P chemistry analyzer (Roche, Basel, Switzerland). Fasting blood sugar was assessed with a hexokinase method. ${ }^{25}$

\section{Result}

Data are presented as average $\pm \mathrm{SD}$. The mean difference was statistically significant $(\mathrm{P}<0.05)$ (Table 1$)$.

Table I Age of the study patients $(n=100)$

\begin{tabular}{llll}
\hline & $\begin{array}{l}\text { Premenopause } \\
\text { group (50) }\end{array}$ & $\begin{array}{l}\text { Postmenopause } \\
\text { group (50) }\end{array}$ & P value \\
\hline Age & $38.2 \pm 5.9$ & $50 \pm 1.03$ & 0.001 \\
\hline
\end{tabular}

Table 2 shows that the data is presented as $\pm \mathrm{SD}$. Differences in anemia were statistically significant $(\mathrm{P}<0.05)$. Some differences were not statistically significant $(\mathrm{P}>0.05)$.

Table 2 Baseline characteristics of study patients $(n=100)$

\begin{tabular}{llll}
\hline & $\begin{array}{l}\text { Premenopause } \\
\text { group (50) }\end{array}$ & $\begin{array}{l}\text { Postmenopause } \\
\text { group (50) }\end{array}$ & P value \\
\hline Anemia & $0 \%$ & $6 \%(3)$ & 0.001 \\
Jaundice & $0 \%$ & $0 \%$ & 0.5 \\
Oedima & $0 \%$ & $0 \%$ & 0.5 \\
Temperature & $0 \%$ & $0 \%$ & 0.05 \\
\hline
\end{tabular}

Table 3 shows that the mean of the data is presented as $\pm \mathrm{SD}$. The mean difference of $\mathrm{DM}$ was statistically significant $(\mathrm{P}<0.05)$. Other differences were not statistically significant $(\mathrm{P}>0.05)$.

Table 3 Presenting illness of the study patients $(n=100)$

\begin{tabular}{llll}
\hline & $\begin{array}{l}\text { Premenopause } \\
\text { group (50) }\end{array}$ & $\begin{array}{l}\text { Postmenopause } \\
\text { group (50) }\end{array}$ & P value \\
\hline DM & $10 \%(5)$ & $6 \%(3)$ & 0.001 \\
Asthma & $2 \%(1)$ & $0 \%$ & 0.3 \\
HTN & $6 \%(3)$ & $10 \%(5)$ & 0.4 \\
\hline
\end{tabular}

Table 4 shows data presented as $\pm \mathrm{SD}$. The difference in systolic $\mathrm{BP}$ level was statistically significant $(\mathrm{P}<0.05)$. Other mean differences were not statistically significant $(\mathrm{P}>0.05)$. 
Table 4 Physical examination result of the study patients

\begin{tabular}{llll}
\hline & $\begin{array}{l}\text { Premenopause } \\
\text { group (50) }\end{array}$ & $\begin{array}{l}\text { Postmenopause } \\
\text { group (50) }\end{array}$ & P value \\
\hline Systolic BP & $128.6 \pm 1.05 \mathrm{~mm} \mathrm{of} \mathrm{Hg}$ & $134 \pm 1.2 \mathrm{~mm}$ of $\mathrm{Hg}$ & $0.00 \mathrm{I}$ \\
Diastolic BP & $74.6 \pm 1.3 \mathrm{~mm} \mathrm{of} \mathrm{Hg}$ & $74.6 \pm 1.7 \mathrm{~mm} \mathrm{Hg}$ & 0.5 \\
Weight & $55.3 \pm 8.8$ & $55.6 \pm 5.9$ & 0.5 \\
\hline
\end{tabular}

Table 5 shows that the data are presented as $\pm \mathrm{SD}$. The mean difference of TC was not statistically significant $(\mathrm{P}>0.05)$. The other mean difference was statistically significant $(\mathrm{P}<0.05)$.

Table 5 Lipid profile of the study patients

\begin{tabular}{llll}
\hline & $\begin{array}{l}\text { Premenopause } \\
\text { group (50) }\end{array}$ & $\begin{array}{l}\text { Postmenopause } \\
\text { group (50) }\end{array}$ & P value \\
\hline TC & $191 \pm 2.3$ & $194 \pm 5.2$ & 0.3 \\
TG & $132 \pm 7.2$ & $156 \pm 7.5$ & 0.001 \\
LDL & $122 \pm 2.32$ & $111 \pm 3.2$ & 0.001 \\
HDL & $42 \pm 9.2$ & $78 \pm 2$ & 0.001 \\
\hline
\end{tabular}

\section{Discussion}

This study presents a unique view of reproductive aging, without natural aging. We have observed a combination of menstrual risk factors for CVD between multiple age groups of the year, indicating that this relationship cannot be explained by the effects of aging in sequence alone. The magnitude of the variability in risk factors for CVD between menstrual status groups varies with age, emphasizing the additional role of aging in chronological order. In light of these results, it appears that both age sequence and menstrual status contribute to the risk profile of CVD in older women.

Naturally, postmenopausal women had lower rates of SBP remodeling at a higher age than premenopausal, peri, or postmenopausal women. Previous reports have identified fertility levels that are associated with high blood pressure, with some reporting a lack of any organization after years of adjustment. ${ }^{26,27} \mathrm{~A}$ longitudinal study in 193 women was the first to find a lower SBP level after comparisons with premenopausal women, considering that the ovarian narrowing area showed a protective effect on the increase in SBP levels. ${ }^{28}$ Structurally, we cannot confirm these assumptions, but our results contradict previous reports of severe hypertension in the peri- and postmenopausal states. ${ }^{26,27}$

Previous research on the changes associated with menopause in CVD, death, and risk is difficult to interpret in part due to inadequate correction of critical factors such as age, anemia, jaundice, asthma, and obesity-associated with all menstruation. menstruation and heart disease. Other behavioral problems include misdiagnosis of menstruation and unstable limitations due to the small number of women with severe heart disease.

As they grow older, women have a chance to develop DM: at 38.2 years \pm 5.9 to $5 \pm 1.03$, about $6 \%$ to $10 \%$ of women have DM. PMW diabetes is three times more likely to develop CAD or stroke than women without diabetes. Also, a woman with diabetes is four times more likely to die from MI than a man with diabetes. ${ }^{28-31}$

The increased level of CAD in PMW appears to be related, in part, to the loss of the protection provided by chronic estrogen. This finding is supported by the significant increase in CAD seen in women after menstrual surgery. ${ }^{32}$ On the other hand, high incidences of high blood pressure and hyperlipidemia, and high body mass index are elevated after menopause. ${ }^{33}$

When lipid levels are affected, the previous findings are not hidden and are consistent with our results. LDL-c and TC levels are widely thought to be influenced by menstrual changes or to be associated with menstrual status..$^{34,35}$ In fact, the average difference in the LDL-c levels of $122 \pm 2.32$ observed between the previous year and the last period was in line with the scope we have observed. Decreased estradiol throughout menopausal changes may not play a role in this, as TC and LDL-c levels are incompatible with complete or free estradiol in 50 postmenopausal women. On the other hand, post-menopausal hormone therapy was associated with a better lipid profile compared with placebo in a meta-analysis of 50 trials.

In our population, differences in LDL-c and TC groups between menstrual status groups have only become apparent after age 45, after which LDL-c and TC levels increased significantly in peri- and postmenopausal groups. While rapid increases in lipid levels were previously linked to menopause, our results suggest that chronological aging is equally involved. Indeed, the adjusted difference in TC and LDL-c values over the 45-50 age range was proportional to the maximum difference observed between menstrual status groups. It is possible that, with age, the availability of compensation measures to reduce hyperlipidemia decreases. ${ }^{36,37}$

The insulin resistance due to DM is responsible for increased hepatic synthesis of triglyceride- (TG-) lipoproteins rich and rapid removal of high-density lipoproteins cholesterol (HDL-C). ${ }^{38,39}$ Thus, dyslipidemia in women with postmenopausal diabetes is characterized by high plasma TG, lowered HDL-C, and elevated low lipoprotein (LDL) levels. ${ }^{40}$

Abnormalities in coagulation and fibrinolysis are commonly seen in type $2 \mathrm{DM}$ including cardiovascular risk indicators such as fibrinogen, factor VII, von Willebrand factor, tissue anti-plasminogen activator antigen, and plasminogen activator inhibitor-1 (PAI- 1) antigen activity. ${ }^{41,42}$ In addition, increased peri- and postmenopausal increases have been reported in the combination and reduction of fibrinolysis. Although it has been shown that premenopausal women produce less thromboxane B2 than men of average age, women show a similar increase in prostaglandin levels during menopause, and such an increase is not yet found in men. ${ }^{43}$

\section{Conclusion}

In conclusion, it seems that only major clinical trial can help to determine the amount of dose for women and provide the information about HRT where it is necessary or not. The prevention of cardiovascular diseases depends on several factors such as change in lifestyle, particularly strict control of diabetics because it is difficult for estrogen to mitigate all kinds of cardiovascular risk.

\section{Acknowledgments}

None.

\section{Funding}

None.

\section{Conflicts of interest}

The authors report no declarations of interest. 


\section{References}

1. Mendelsohn ME, Karas RH. The protective effects of estrogen on the cardiovascular system. N Engl J Med. 1999;340(23):1801-1811.

2. Reddy Kilim S, Rao Chandala S. A comparative study of lipid profile and oestradiol in pre- and post-menopausal women. J Clin Diagn Res. 2013;7(8):1596-1598.

3. Kumar S, Shah C, Oommen ER. Study of cardiovascular risk factors in pre and postmenopausal women. International Journal of Pharma Sciences and Research. 2012;3(12):560-570.

4. Deepthi S, Naidu J, Narayan AR. Relationship between estrogen and lipid profile status in postmenopausal women. International Journal of Applied Biology and Pharmaceutical Technology. 2012;3(3):230-234.

5. Guetta V, Cannon III RO. Cardiovascular effects of estrogen and lipid-lowering therapies in postmenopausal women. Circulation. 1996;93(10):1928-1937.

6. Peters HW, Westendorp ICD, Hak AE, et al. Menopausal status and risk factors for cardiovascular disease. J Intern Med. 1999;246(6):521-528.

7. Shende SS, Iyer C, Mahajan VV, et al. Effect of duration on lipid profile status in post-menopausal women. Health. 2014;2(3):90-94.

8. Cardiovascular diseases (CVDs). 2016.

9. F'elix-Redondo FJ, Grau M, Fern'andez-Berg'es D. Cholesterol and cardiovascular disease in the elderly. Facts and gaps. Aging Dis. 2013;4(3):154-169.

10. Derby CA, Crawford SL, Pasternak RC, et al. Lipid changes during the menopause transition in relation to age and weight: the Study of Women's Health Across the Nation. Am J Epidemiol. 2009;169(11):1352-1361.

11. Ifueko OD. Serum lipid profile of postmenopausal women in Sapele, Delta State, Nigeria. Journal of Medicine and Medical Research. 2013;1(1):913.

12. Prevention of cardiovascular disease: pocket guidelines for assessment and management of cardiovascular risk (WHO). WHO; 2007.

13. Ossewaarde ME, Bots ML, Verbeek AL. Age at menopause, cause-specific mortality and total life expectancy. Epidemiology. 2005;16:556-562.

14. Rossouw JE, Anderson GL, Prentice RL. Risks and benefits of estrogen plus progestin in healthy postmenopausal women: principal results from the Women's Health Initiative randomized controlled trial. JAMA. 2002;288:321-333.

15. Baber RJ, Panay N, Fenton A. The IMS Writing Group 2016 IMS Recommendations on women's midlife health and menopause hormone therapy. Climacteric. 2016;19(2):109-150.

16. Biglia N, Cagnacci A, Gambacciani M, et al. Vasomotor symptoms in menopause: a biomarker of cardiovascular disease risk and other chronic diseases? Climacteric. 2017;20(4):306-312.

17. Verdecchia P, Porcellati C, Schillaci G, et al. Ambulatory blood pressure: an independent predictor of prognosis in essential hypertension. Hypertension. 1994;24:793-801.

18. Reis SE, Gloth ST, Blumenthal RS, et al. Ethinyl estradiol acutely attenuates abnormal coronary vasomotor responses to acetylcholine in postmenopausal women. Circulation. 1994;89:52-60.

19. Negre-Salvayre A, Pieraggi MT, Mabile L, et al. Protective effect of 17-b-estradiol against the cytotoxicity of minimally oxidized LDL to cultured bovine aortic endothelial cells. Atherosclerosis. 1993;99:209217.

20. Bush TL, Barrett-Connor E, Cowan LD, et al. Cardiovascular mortality and noncontraceptive use of estrogen in women: results from the Lipid Research Clinics Program Follow-up Study. Circulation. 1987;75:11021109.
21. Schillaci G, Verdecchia P, Zampi I, et al. Non-invasive ambulatory BP monitoring during night: randomised comparison of different reading intervals. J Hum Hypertens. 1994;8:23-27.

22. Grodstein F, Stampfer MJ, Manson JE, et al. Postmenopausal estrogen and progestin use and the risk of cardiovascular disease. $N$ Engl J Med. 1996;335:453-461.

23. Hu FB, Grodstein F, Hennekens CH, et al. Age at natural menopause and risk of cardiovascular disease. Arch Intern Med. 1999;159:1061-1066.

24. Scholtens S, Smidt N, Swertz MA, et al. Cohort Profile: LifeLines, a threegeneration cohort study and biobank. Int J Epidemiol. 2015;44(4):11721180 .

25. Slagter SN, van Vliet-Ostaptchouk JV, Vonk JM, et al. Combined effects of smoking and alcohol on metabolic syndrome: the LifeLines cohort study. PLoS One. 2014;9(4):e96406.

26. Zanchetti A, Facchetti R, Cesana GC, et al. Menopause-related blood pressure increase and its relationship to age and body mass index: the SIMONA epidemiological study. J Hypertens. 2005;23(12):2269-2276.

27. Staessen J, Bulpitt CJ, Fagard R, et al. The influence of menopause on blood pressure. J Hum Hypertens. 1989;3(6):427-433.

28. Wingard DL, Barrett-Connor E. Heart disease and diabetes in Diabetes in America. In: Harris MI, Courie CC, Beiber G, editors. NIH Publication No. 95-1468, Washington, DC, USA: US Government Printing Office; 1995.

29. Kannel WB, McGee DL. Diabetes and cardiovascular disease. The Framingham study. The Journal of the American Medical Association. 1979;241(19):2035-2038.

30. Greenland P, Reicher-Reiss H, Goldbourt U, et al. In-hospital and 1-year mortality in 1,524 women after myocardial infarction. Comparison with 4,315 men. Circulation. 1991;83(2):484-491.

31. Harris MI, Flegal KM, Cowie CC, et al. Prevalence of diabetes, impaired fasting glucose, and impaired glucose tolerance in U.S. adults: The Third National Health and Nutrition Examination Survey, 1988-1994. Diabetes Care. 1998;21(4):518-524.

32. Barrett-Connor E, Bush TL. Estrogen and coronary heart disease in women. JAMA. 1991;265(14):1861-1867.

33. Laakso M. Glycemic control and the risk for coronary heart disease in patients with non-insulin-dependent diabetes mellitus: the Finnish studies. Annals of Internal Medicine. 1996;124(1):127-130.

34. Van Beresteyn EC, Hof MA v t, De Waard H. Contributions of ovarian failure and aging to blood pressure in normotensive perimenopausal women: a mixed longitudinal study. Am J Epidemiol. 1989;129(5):947955.

35. Bonithon-Kopp C, Scarabin PY, Darne B, et al. Menopause-related changes in lipoproteins and some other cardiovascular risk factors. Int J Epidemiol. 1990;19(1):42-48.

36. Auro K, Joensuu A, Fischer K, et al. A metabolic view on menopause and ageing. Nat Commun. 2014;5:4708.

37. Matthews KA, Crawford SL, Chae CU, et al. Are changes in cardiovascular disease risk factors in midlife women due to chronological aging or to the menopausal transition? J Am Coll Cardiol. 2009;54(25):2366-2373.

38. Olefsky JM, Farquhar JW, Reaven GM. Reappraisal of the role of insulin in hypertriglyceridemia. Am J Med. 1974;57(4):551-560.

39. Frénais R, Ouguerram K, Maugeais C, et al. High density lipoprotein apolipoprotein AI kinetics in NIDDM: a stable isotope study. Diabetologia. 1997;40(5):578-583.

40. Siegel RD, Cupples A, Schaefer EJ, et al. Lipoproteins, apolipoproteins, and low-density lipoprotein size among diabetics in the Framingham offspring study. Metabolism. 1996;45(10):1267-1272. 
41. Schneider DJ, Nordt TK, Sobel BE. Attenuated fibrinolysis and accelerated atherogenesis in type II diabetic patients. Diabetes. 1993;42(1):1-7.

42. Lee AJ, Lowe GDO, Smith WCS, et al. Plasma fibrinogen in women: relationship with oral contraception, the menopause and hormone replacement therapy. Br J Haematol. 1993;83(4): 616-621.
43. Balteskard L, Brox JH, Osterud B. Thromboxane production in the blood of women increases after menopause whereas tumor necrosis factor is reduced in women compared with men. Atherosclerosis. 1993;102(1):9198 . 